\title{
CRITERIOS PARA LA COMPOSICIÓN DE UNA HISTORIA DE LA FILOSOFÍA CHIHUAHUENSE ${ }^{\mathrm{I}}$
}

JORGE ORDÓÑEZ

\section{RESUMEN}

L a historiografía de la filosofía es un área de investigación poco cuidada en México y en algunas tradiciones importantes del Occidente. Sus aportaciones no solo se reducen al campo metodológico, sino que representan un ejercicio de validación que fortalece el autoconocimiento que tiene de sí la filosofía. En este artículo se proponen algunos elementos para esbozar las bases de una historiografía del pensamiento chihuahuense, observando de cerca los productos e impacto que estos han tenido en el ámbito local y foráneo.

Palabras clave: Historiografía del pensamiento, pensamiento chihuahuense, filosofía mexicana

\begin{abstract}
In Mexico and some important western traditions, the historiography of Philosophy is a research little cared of area. Because its contributions are beyond methodological field, and are an exer-

1 El texto se integró a partir de dos ponencias, una presentada en la I Reunión Estatal del Seminario Internacional de Historia y Filosofía de las Religiones (UACJ, 12 de abril de 2016); la otra, en el foro del C.A. Metodología, Representaciones y Humanidades, compuesto por profesores de la Licenciatura en Filosofía de la Facultad de Ciencias Sociales y Humanidades (UASLP, 5 de mayo de 2016).
\end{abstract}


cise that provides validation to Philosophy's self-knowledge. In this article some topics to sketch out the basement for a Historiography of Chihuahuan thought are proposed. Making a close look of its products and their impact that have had around local and foreign ambit.

Keywords: Historiography of thought, chihuahuan thought, mexican philosophy

Es sorprendente que la filosofía, tan dispuesta a mostrar a los historiadores o a los geógrafos cómo han de practicar su arte y a los científicos cómo abordar los usos correctos de la epistemología, caiga en la trampa de negarse aplicar en su parroquia lo que enseña en las vecinas. Pues, que yo sepa, la filosofía no pone a prueba las certezas de su secta sometiendo la historia de su disciplina al fuego cruzado de un trabajo crítico capaz de explicar por qué se la ha escrito de determinada manera.

(Minchel Onfray

Las sabidurías de la Antigüedad. Contrahistoria de la filosofía)

El trabajo que aquí se expone no tiene la intención de fijar la historia de la filosofía en el estado de Chihuahua, ni siquiera busca esbozar una historia poco rigurosa. El cometido de mi disertación consiste en meditar sobre la llamada filosofía académica desarrollada en los últimos cuarenta años (1976-2016). Para lograr tal propósito, presentaré el esqueleto de una historiografía de las ideas, una vía de comprensión de muchas posibles; por ello, el título refiere "criterios" que, a mi entender, debería cumplir una forma de pensar que aspira entrar en la categoría de filosofía. "Criterios" factores que nutren el juicio, es decir, son la base de la aproximación más o menos equilibrada a ciertas circunstancias. Partiré de una noción operativa de la disciplina para hacer los ajustes necesarios que permitan amoldarse al medio chihuahuense. Estoy cierto que hay filósofos chihuahuenses y de buena cepa, de lo que no estoy tan seguro es de la existencia de una filosofía nuestra. No en el sentido académico, partícipe del diálogo con instituciones, organismos y comunidades nacionales y extranjeras. Evaluada con rigurosidad, fundada en propuestas claras más que en promesas 
o castillos en el aire. Concentrada en lo local y abierta al mundo entero, logrando un punto de equilibrio que le impida caer en una actitud aldeana o en la pose de ser cosmopolita. Una filosofía chihuahuense sería aquella que aportase temas, planteamientos y reflexiones dentro y fuera del estado. Pero, su contribución no se haría solo a partir de individuos -como ha sucedido y sucede en la actualidad-, sino, mediante grupos de investigación activos con historia y porvenir. Debería responder, pues, una pregunta contundente y dolorosa: ¿qué se abona a la filosofía mexicana, latinoamericana y mundial desde Chihuahua?

En las siguientes páginas, se describirán algunas herramientas que podrían ayudar a la creación de una historiografía del pensamiento en Chihuahua. Un puñado de rubros críticos para justificar la integración del quehacer filosófico local a los anales del pensamiento.

\section{ALGUNAS LÍNEAS METODOLÓGICAS A SEGUIR}

El esquema buscado no puede adscribirse a una historiografía tradicional diseñada para modelos europeos, la filosofía de las escuelas occidentales opera mediante otra dinámica y se finca en un contexto social, económico y político diferente al nuestro. Ello no significa que el pensamiento que se produce fuera de Europa debe revisarse con laxitud o poca rigurosidad, todo lo contrario. Es por eso que la pregunta "dolorosa e incómoda" sea un instrumento para explorar la posibilidad de incluir el filosofar chihuahuense dentro del catálogo de la filosofía del mundo. El pensamiento chihuahuense ha de abordarse como parte viva del espíritu mexicano y latinoamericano, teniendo presente que es confeccionado a partir de condiciones históricas y antropológicas específicas. Por ejemplo, la lejanía geográfica con la capital del país, centro gravitatorio por excelencia de la vida nacional. A pesar que en la actualidad se ha salvado el problema de la distancia espacial mediante recursos tecnológicos, resulta imposible trasladar el ambiente cosmopolita de la Ciudad de México al interior de la república. La inmensa oferta cultural, la interacción con personas de todo el mundo, la existencia de círculos de inves- 
tigación de reputación mundial, o, la disponibilidad de archivos, bibliotecas y casas editoriales, son elementos que no integran el ámbito de los filósofos chihuahuenses. Igualmente, otro aspecto característico de nuestro estado es la vocación tecnológica que tiene el norte del país, reflejada en la proliferación de escuelas y facultades de administración, ingeniería y ciencias aplicadas a procesos productivos. Al revisar el desenvolvimiento de carreras como mecatrónica, mercadotécnica, geoinformática, ecología o ingeniería aeronáutica, se puede observar que en unos años se han hecho fuertes vínculos con el sector industrial, ha surgido una comunidad académica con especialistas locales y foráneos; se han abierto programas de posgrado de calidad, además de consolidar líneas de investigación mediante patentes, otorgamiento de premios de investigación por instancias mexicanas y extranjeras, así como la publicación de artículos científicos en revistas nacionales e internacionales.

En lo tocante al rubro historiográfico de la filosofía, es poco lo que se ha hecho en México sobre este particular, existe actividad intensa en el terreno histórico de las ideas, mas no en su contraparte reflexiva. El pensamiento novohispano ha sido una de las excepciones, tratado con maestría por investigadores como Carmen Rovira, ${ }^{2}$ Mauricho Beuchot ${ }^{3}$ y Bernabé Navarro, ${ }^{4}$ por mencionar solo a los más destacados. Entre las principales aportaciones conseguidas, está repensar a México y América, abriendo filones de investigación-revisión de la filosofía de la humanidad en conjunto. Sin embargo, para el pensamiento chihuahuense contemporáneo, es poco lo que puede retomarse de los estudios coloniales porque

2 Puede consultarse la extensa bibliografía que la profesora Rovira ha publicado sobre el tema en: http://dcsh.izt.uam.mx/cen_doc/cefilibe/images/banners/enciclopedia/Diccionario/Autores/FilosofosMexicanos/Rovira_Gaspar_Ma_Del_Carmen.pdf

3 Cf. Comentarios lucidísimos al texto de Pedro Hispano. UnAm. México, 1986. Filósofos dominicos novohispanos (entre sus colegios y la universidad). unAm. México, 1987. En coautoría con Walter Redmond: Pensamiento y realidad de fray Alonso de la Vera Cruz. unAm. México, 1987. Filósofos mexicanos del siglo xviII. unAm. México, 1995. Historia de la filosofía en el México colonial. Herder. Barcelona, 1996. Y Filosofía, neobarroco y multiculturalismo. Ítaca. México, 1997.

4 Cf. Cultura mexicana moderna en el siglo XviII. unAm. México, 1986. Y Filosofía y cultura novohispanas. UnAM. México, 1998. 
se concentran en circunstancias diferentes a las que aquí se dan. Sucede lo mismo con historiografías de la filosofía mexicana del siglo xix y xx-XXI, la mayoría de ellas orientadas al quehacer intelectual de la Ciudad de México y la zona centro del país.

En 1946, José Fuentes Mares escribió un pequeño artículo titulado "Trayectoria del pensamiento filosófico en el Méjico de nuestros días". ${ }^{5}$ Su recuento inicia con Antonio Caso cerrando con Francisco Larroyo y él. El principio articulador del texto consiste en afirmar que en México no existía entonces una filosofía, sino filósofos. Una consideración que no debe tomarse a la ligera, porque a pesar de la solidez del medio filosófico en que se formó Fuentes Mares, prefiere no hablar de una filosofía mexicana. Observemos cómo estaba compuesto tal entorno. Podemos identificar una tradición que se remonta a Gabino Barreda -quien estudió con Comte en Francia-, maestro de Justo Sierra, quien a su vez tuvo como discípulos a Antonio Caso, Alfonso Reyes y José Vasconcelos, por mencionar tan solo a algunos de los más destacados. Ellos a su vez, fueron guía de nuevas generaciones, entre las que se encontraba la de Fuentes Mares. En la capital se forjaron instituciones clave para el México contemporáneo, creadas como resultado de las ideas de las grandes mentes. La Escuela Nacional Preparatoria, lo que hoy es la UNAM y su Facultad de Filosofía y Letras, la SEP, posteriormente, el Colegio de México y el Fondo de Cultura Económica. El Ateneo de la Juventud y la presencia de profesores españoles exiliados, la fundación de revistas de creación filosófica en las que se reseñaba y discutía el trabajo de los colegas, además, la publicación de obras filosóficas mexicanas y extranjeras. Si aún con todo este virtuoso entramado de circunstancias Fuentes Mares no se permite hablar de una filosofía mexicana, considero que referirse a una filosofía chihuahuense sería pretencioso.

Rolando Picos Bovio y Miguel de la Torre, publicaron en años recientes una magnífica obra titulada Inventario de la filosofía en

5 Publicado originalmente en la Revista de Estudios Americanos, Núm. 1, Vol. 1, Sevilla, 1946. -Puede encontrarse la reproducción del texto en el Vol. 5 de las Obras de Fuentes Mares, pp. 455-473. uACJ. Ciudad Juárez, 2012. 
Nuevo León. Filosofía y filósofos en Monterrey ${ }^{6}$ que se distingue por su originalidad y pertinencia. La investigación inicia con una evocación a la enseñanza de la filosofía en escuelas religiosas a principios del siglo XVIII, refiere el pronunciamiento de Alfonso Reyes sobre la fundación de la universidad del estado en la primera mitad del siglo xx, posteriormente, recoge el trabajo de académicos que han formado parte de la FFyL de la UANL. El método expositivo consiste en describir las condiciones políticas y sociales que se dieron en la Facultad en los últimos cuarenta y cinco años, posteriormente, se transcriben entrevistas hechas a los filósofos y se pone a disposición del lector la producción y méritos de cada uno. Por ejemplo, Severo Iglesias González de quien se han editado varios volúmenes de sus Obras, 7 Tomás González de Luna que estudió en la URSs, y, Alfonso Rangel Guerra, Doctor Honoris Causa y distinguido con el Premio Internacional Alfonso Reyes. Quizá el caso de Monterrey nos sea más cercano, sin embargo, en el contexto filosófico chihuahuense, no existen condiciones paralelas, excepto el caso de Fuentes Mares. Tampoco considero que pueda llevarse a buen puerto una auscultación del ambiente político vinculado con la filosofía en Chihuahua, todavía existe gran resistencia para tratar dicho tema. Hay cacicazgos añejos y otros de reciente creación que impiden el diálogo abierto. Respecto al estudio del pensamiento, el método historiográfico seguido en Nuevo León no podría aplicarse sin las adaptaciones necesarias, ${ }^{8}$ además, es pertinente mencionar que el propósito de la obra referida es construir una suerte de historia de la filosofía, mientras que lo que aquí se intenta es proponer criterios historiográficos.

\footnotetext{
6 UANL/Juan Pablos, México, 2014.

7 Aparecidas en coedición por Morevallado-Universidad Michoacana de San Nicolás Hidalgo, 2007.

8 Entre los ajustes metodológicos que debería recibir una historiografía del pensamiento chihuahuense, de miras más amplias que las de este breve artículo, está la caracterización del período novovizcaíno. Establecer criterios que permitan atajar cuestiones como ¿en qué medida la evangelización y fundación de misiones obedecía a un mandato y hasta qué punto podría considerarse filosofía práctica? Lo poco que se ha investigado sobre este particular se le debe a Dizán Vázquez Loya; uno de sus trabajos más importantes es Las misiones franciscanas en Chihuahua. Pistas y referencias para su investigación. UACJ. Ciudad Juárez, 2004. Disponible en http://www.uacj.mx/UEHS/Documents/cdi3.pdf
} 
El profesor Alberto Saladino García es un filósofo que se ha concentrado en desarrollar una historiografía de la ciencia y la filosofía de México y América Latina. Su labor se ha enfocado en el pensamiento ilustrado novohispano y contemporáneo, dichas investigaciones se caracterizan por el voluminoso material bibliográfico que las respalda. ${ }^{9}$ Mediante la lectura sistemática de obras, Saladino identifica los momentos clave que definen épocas y escuelas, expone las tesis que son objeto de diálogo y debate entre tradiciones; explora el surgimiento de ideas acotando los componentes extranjeros y locales que las integran. El texto, ya científico, ya filosófico, es para Saladino un punto en el que convergen diversos factores, dejando atrás el tratamiento de la literatura filosófica en tanto que letra muerta. La obra es un indicador del quehacer humano, resultado de inquietudes y esfuerzo sostenidos. La obra, más que responder a una estadística historiográfica es manifestación nítida de la vida espiritual de individuos y comunidades. Para este ensayo, he retomado la idea de obra filosófica propuesta por Alberto Saladino, extendiendo su dimensión contextual a otros productos del ejercicio intelectual, como encuentros, congresos o grupos de trabajo. Para encuadrar los aspectos que componen el medio que envuelve a los productos, sugiero una serie de preguntas críticas. Los interrogantes están encaminados a comprender el significado circunstancial de las manifestaciones del pensamiento chihuahuense, entiéndase como invitaciones al lector a la reflexión. Dado que nos concentraremos en el pensamiento construido en el ámbito de la academia, considero necesario remitirnos a algunos criterios seguidos por organismos nacionales que evalúan el desempeño de investigadores de todas las áreas del saber humano, incluida la filosofía. La contribución a la disciplina, la trascendencia de los estudios desarrollados y la constancia del trabajo son factores imprescindibles para definir cuerpos académicos, redes y líneas de investigación.

9 Entre los trabajos de Saladino en los que puede encontrarse reflejada su metodología están: Dos científicos de la Ilustración hispanoamericana. J.A. Alzate y F.J. Caldas. UNAM. México, 2010. Elementos para una teoría latinoamericana sobre historia de la ciencia. UAEM. Toluca, 2015. Revindicar la memoria. Epistemología y metodología sobre la historia de la filosofía en América Latina. UAEM/UnAM. Toluca, 2012. 
Como apunté antes, en Chihuahua existen filósofos que producen pensamiento de manera más o menos independiente. Un indicador de ello es que aún las figuras más reconocidas de la filosofía en Chihuahua (Federico Ferro Gay, José Fuentes Mares y Arturo Rico Bovio) son poco estudiadas. Propongo el siguiente ejercicio, hágase un conteo en el estado de los cursos universitarios, tesis y reseñas versados sobre ideas de filósofos chihuahuenses; puede extenderse la búsqueda más allá de los tres nombres citados. La atención que regionalmente se brinda a nuestros filósofos arroja indicios sobre el arraigo que tiene aquí la disciplina.

\section{DELIMITACIÓN DE CRITERIOS}

Expondré sucintamente algunos rubros sugeridos para la composición de una historiografía de las ideas en Chihuahua.

1) Temporalidad y detonantes: El período de revisión propuesto comprende los últimos cuarenta años, lo he delimitado así porque en él se han dado procesos que deberían constituir un detonante para la fundación, proyección, y consolidación del pensamiento chihuahuense, entiéndase filosofía académica. Entre ellos son de mencionarse: i) los primeros 15 años de la fundación de la FFyL de la UACH (1978), ${ }^{10}$ ii) la salida de Federico Ferro Gay de la UACH (1984), iii) la primera membresía al sNi de un filósofo chihuahuense (2005) y la posterior aceptación de otros investigadores en dicho organismo, iv) el auge de las publicaciones filosóficas en el estado, v) la organización de congresos de filosofía y áreas afines (v. gr. XXXI Encuentro Nacional de Estudiantes y Pasantes de Filosofía, Chihuahua, 2015;11 la Olimpiada Estatal de Lógica, Chihuahua 2014:12 II Encuentro

10 Cf. "La historia de la Escuela de Filosofía y Letras" de Ferro Gay. Contenido en Lo divino en lo humano, pp. 223-229.

11 Cf. http://www.redhumanidades.mx/pdf/plan_trabajo_conefi.pdf, http://www. uach.mx/noticias/2015/04/14/XXXI_congreso_filosofia/, http://www.oem.com. mx/elheraldodechihuahua/notas/n3789180.htm

12 Cf. http://www.uach.mx/noticias/2014/04/29/uach_cede_olimpiadas_logica/ 
Regional de Filosofía, Chihuahua, 2013:13 VI Congreso Nacional de Filosofía, Chihuahua, 1991; y, I Congreso Internacional de Filosofía Latinoamericana, Cd. Juárez, 199014), vi) la "profesionalización" de la enseñanza de la filosofía en instituciones de nivel medio superior, vii) la apertura del primer posgrado en filosofía del estado (Maestría en filosofía contemporánea, UACJ, 1986), viii) La fundación de la Cátedra Patrimonial Federico Ferro Gay $(2005)^{15}$ y de la Cátedra de Filosofía y Teoría del Derecho José Fuentes Mares (2012), ${ }^{16}$ ix) la "profesionalización" de la filosofía en el estado, x) participación de estudiantes chihuahuenses de filosofía en el Verano de la Investigación Científica, xi) la muerte de José Fuentes Mares (1986) y de Federico Ferro Gay (2006), ${ }^{17}$ xii) el primer medio siglo de la fundación de la FFyL de la $\left.\mathrm{UACH}^{18}{ }^{18} \mathrm{xiii}\right)$ la filiación de varios chihuahuenses a la AFM, OFM y la AMC, xiv) el otorgamiento del Premio Chihuahua a un trabajo de filosofía, xv) la publicación de las Obras de Fuentes Mares (2006-2012), ${ }^{19}$ xvi) aparición de revistas filosóficas en el

13 Cf. http://ffyl.uach.mx/pdf/programa_segundo_encuentro_filosofia.pdf/- Se publicaron unas memorias de dicho encuentro: Filosofar desde el norte de México. La responsabilidad del futuro. Coordinado por Alejandra Olivas Dávila y Heriberto Ramírez Lujan. UACH. Chihuahua, 2014.

14 Cf. "Declaración de Ciudad Juárez", hecha con motivo del Congreso referido. Publicada en Cuadernos del norte, Núm. 10, julio-agosto, 1990, pp. 44-45. Aparecieron las memorias bajo el título América Latina: identidad y diferencia. Actas del Primer Congreso Internacional de Filosofía Latinoamericana, 1990. UACJ. Cd. Juárez, 1992. Solo tres trabajos locales fueron allí publicados: Federico Ferro Gay: "La situación de la filosofía en nuestra sociedad actual", pp. 42-53, Arturo Rico Bovio: "Propuesta para un rescate crítico de la cultura latinoamericana”, pp. 99-105, y Lorenzo Pérez Álvarez: "Función actual de la filosofía en América Latina", pp. 168-176.

15 Cf. http://www.uacj.mx/sa/ie/Paginas/Catedras-Patrimoniales.aspx

16 Cf. http://www.cifyj.org/p/catedra-de-filosofia-y-teoria.html

17 http://ricardovigueras.blogspot.mx/2006/05/recordando-federico-ferro-gayen-su.html

18 Cf. "50 años de la fundación de la Facultad de Filosofía y Letras de la Universidad Autónoma de Chihuahua" de Luis Nava Moreno, http://elhumanista.net/50anos-de-la-fundacion-de-la-facultad-de-filosofia-y-letras-de-la-universidadautonoma-de-chihuahua/ -Puede encontrarse una breve reseña histórica de la Facultad en http://ffyl.uach.mx/historia.html

19 Reunidas en seis tomos, aunque no son obras completas en el sentido estricto, sí son una muestra importante del trabajo de Fuentes Mares. La colección se compone de la siguiente manera: Volumen 1, Historia: 1) Juárez y los Estados Unidos, 2) Juárez y Europa, 3) Juárez y el imperio, 4) Juárez y la república. Volumen 2, Historia: 1) Poinsett: historia de una gran intriga, 2) Santa Anna, aurora y ocaso de un comediante, 3) Miramón, el hombre, 4)... Y México se refugió en el desierto. Volumen 3 Historia: 1) Don 
estado, xvii) la transición de Escuela a Facultad de Filosofía y Letras en la UACH (1988), xviii) la escritura de las primeras "historias" de la filosofía local, ${ }^{20} \mathrm{y}$, xix) consolidación del primer Cuerpo Académico de estudios filosóficos en el estado (UACJ, 2014). He puesto atención especial en el pensamiento desarrollado dentro del contexto académico no porque sea el único, sino porque es quizá el que cuenta con mayor evidencia documental para ser estudiado.

ب) Comunidades: En Chihuahua se han constituido tres clases de grupos. La primera, dedicada a la divulgación del pensamiento filosófico. Actividad que, de suyo, no es despreciable, dado que los encargados de desarrollarla deben contar con un conocimiento amplísimo de la disciplina, además de tener buenas dotes pedagógicas, de lo contrario, la divulgación se torna vulgarización. En segundo lugar, existen personas dedicadas a la enseñanza formal de la filosofía en programas de pre y posgrado, de una filosofía que no ha sido creada por ellos y que, en ocasiones, tampoco la han estudiado a profundidad. Podría debatirse si en realidad se trata de una divulgación selectiva o de la formación de profesionales en el área. No obstante, tal discusión debe dejarse para otra ocasión. Los dos grupos apuntados no pueden considerarse dentro de una historia de la filosofía dado que su objetivo no es crear pensamiento, sino dar a conocer el que ya existe. Quizá su relevancia sea mayor en el contexto de una historia de la cultura o de la educación;

Sebastián Lerdo de Tejada y el amor, 2) México y España: historia de un conflicto, 3) La emperatriz Eugenia y su aventura mexicana, 4) Génesis del expansionismo norteamericano, 5) Cortés, el hombre, 6) Biografía de una nación. Volumen 4 Ensayo y Cuento: 1) Historia de dos orgullos, 2) Monterrey, una ciudad creadora, 3) México en la hispanidad, 4) Nueva guía de descarriados, 5) Intravagario, 6) Las mil y una noches mexicanas I y II, 7) Chihuahua, un país singular. Volumen 5 Filosofía: 1) Kant y la evolución de la conciencia socio-política moderna, 2) Gabino Barreda, 3) Ley sociedad y política. Ensayo para una valoración de la doctrina de San Agustín en perspectiva jurídico-política de actualidad, 4) "Trayectoria del pensamiento filosófico en el Méjico de nuestros días". Volumen 6 Novela y Teatro: 1) Las memorias de Blas Pavón, 2) Cadenas de soledad, 3) La revolución mexicana, memorias de un espectador, 4) El crimen de la Villa Alegría, 5) Servidumbre, 6) Teatro.

20 Por ejemplo, una sección de Lo divino en lo humano titulada Filosofía en Chihuahua, compuesta por tres trabajos, abre con el conmemorativo de los primeros 15 años de la FFyL, el segundo sobre Pedro Zuloaga, pp. 231-234, y uno dedicado a Porfirio Parra, pp. 235-237. Véase también Porfirio Parra, un chihuahuense universal de Walter Beller Taboada. UACJ, 2010. 
su trascendencia es grande, ubicándolas en el área correspondiente. En tercer lugar, se dice que existen grupos de investigación filosófica dedicados a crear filosofía. Es irresponsable ubicar en esta estatura a células compuestas por titulados en filosofía que hacen trabajo conjunto, no sin antes encontrar sus aportaciones palpables y dar el suficiente tiempo de margen (no menos de diez años) para calcular su justo impacto. No quiero pronunciarme en este particular categóricamente, este campo queda abierto a la meditación y al diálogo.

ث) Profesionalización de la filosofía en el estado: en ningún momento como hoy, en los últimos cuarenta años, ha habido tantos profesionistas con títulos de filosofía en Chihuahua. De licenciatura a postdoctorado, pueden hacerse estadísticas con datos muy concretos. Nunca ha habido tantos afiliados al SNI, ni aparecido la cantidad de libros con tema filosófico académico bajo el sello de editoriales chihuahuenses. En medio de la efervescencia profesionalizante habría que buscar las propuestas filosóficas. Hace más de quince años la UACH, se preocupó por brindarles facilidades a algunos docentes de la FFyL para cursar la Maestría en Filosofía de la Cultura mediante visitas programadas de investigadores de la U. Nicolaíta, sin duda un gran esfuerzo al que el interesado por la historia de las ideas debe dar seguimiento. Revisar el índice de deserciones y egreso, los temas de las tesis defendidas, así como la suerte que corrió cada una de ellas en el terreno editorial. En la UACJ, se abrió y reabrió una Maestría en Filosofía Contemporánea con dos líneas terminales, una en filosofía norteamericana y otra en latinoamericana. Igualmente, hacer una revisión puntual del programa serviría para la configuración de un panorama más claro de lo que sucede en el estado.

ت) Producción filosófica: Dado que nos hemos instalado en el ámbito académico, lo coherente es ceñirse a los esquemas tradicionales seguidos para evaluar el resultado de las investigaciones filosóficas. Por muy burocráticos o enajenantes que se les considere, es importante observarlos. Aunque el pensamiento académico se emancipe es imposible desligarlo por completo de lo institucional. Las publicaciones son evidencia de la labor 
desempeñada, además, los estudios universitarios de filosofía con frecuencia se centran en libros como fundamento de análisis; hablemos, entonces, de dichos materiales. No busco construir un catálogo de los textos chihuahuenses de las últimas cuatro décadas -que, en realidad, no sería una lista muy larga de títulos- lo que propongo son las coordenadas para ubicar las obras dentro del acervo local. La temática de la literatura filosófica podría clasificarse en dos grandes campos, la primera y más cultivada, de corte histórico. Integrada por manuales de historia de la filosofía, ensayos sobre filósofos y tradiciones, además de homenajes y estudios conmemorativos. La segunda, se compone por trabajos de creación filosófica. Para hacer el encuadre de dichos materiales, sugiero algunas preguntas. Los libros de tema filosófico editados en los últimos años ¿han sido reseñados por chihuahuenses o por gente de fuera del estado? Sobre este particular cabe mencionar un caso atípico. César Santiesteban publicó en Signos filosóficos (2008) una reseña ${ }^{21}$ sobre el libro de Esteban Gasson Lara El Informe Natorp. El inicio de la interpretación heideggeriana de Aristóteles. ${ }^{22} \mathrm{Un}$ chihuahuense reseñando a un paisano en las páginas de una revista indexada es un hecho singular, y, hasta donde sé, no tiene antecedentes. Lamentablemente es un ejemplo aislado. Más allá de las reseñas, ¿han sido citados, comentados o debatidos trabajos de chihuahuenses en investigaciones filosóficas? ¿Son parte de la bibliografía de cursos dentro y fuera del estado? La mayoría de los textos publicados en Chihuahua son colectivos, ${ }^{23}$ ¿cuántos de sus autores solo colaboran en esta

21 Signos filosóficos, Vol. X, Núm. 20, julio-diciembre de 2008, pp. 161-167. UAm Iztapalapa. Disponible en http://www.redalyc.org/articulo.oa?id=34311599009

22 Ichicult, Chihuahua, 2008.

23 E.g.: 1) Filosofía del septentrión. Compiladores César Santiesteban y Carlos Montemayor. UACH/Aldus. Chihuahua, 2005. 2) Encuentros con Nietzsche. Editado por Esteban Gasson Lara. UACH, Chihuahua, 2002. 3) Encuentros con Wittgenstein. Compilado por Esteban Gasson Lara. UACH, Chihuahua, 2008, y 4) Ser y tiempo. Comentario introductorio a la obra de Martin Heidegger. Coordinado por César Santiesteban, UACH. Chihuahua, 2014. 5) Fronteras y reconstrucciones en la filosofía de la ciencia. Editado Víctor Hernández Márquez. UACJ. Ciudad Juárez, 2013. 6) Hermenéutica y epistemología en perspectiva histórica. Compilado por Roberto Estrada Olguín y Víctor Hernández Márquez. UACJ. Ciudad Juárez, 2014. 7) La multiplicidad de Rousseau. Editado por Roberto Sánchez Benítez y Víctor Hernández Márquez, Anthropos-UACJ, 2016. 
clase de libros? Los temas elegidos ¿son parte de las líneas de investigación consolidadas o se participa oportunamente alrededor de un tópico propuesto?

Existen diversos espacios para publicar libros, el Ichicult lanza una convocatoria anual en la que han cabido trabajos filosóficos en el reglón de ensayo. Tanto la UACH como la UACJ mantienen un programa anual de publicaciones, entre ellas es quizá donde se concentre la mayor cantidad de títulos del área.

Pasando a los artículos, de lo que se produce en Chihuahua ¿cuántos se publican en revistas de reconocimiento nacional e internacional? ¿Cuántos chihuahuenses fungen o han fungido como árbitros de revistas indexadas? Llama la atención que a la fecha no se haya consolidado una sola revista académica de filosofía en el estado, compuesta por un sólido cuerpo de revisores bien habilitados e incluida en índices nacionales e internacionales. Han aparecido revistas en las que pueden encontrarse escritos de relevancia filosófica, sin embargo, son los menos. En promedio, son de una extensión de no más de diez cuartillas y están enfocados a la divulgación. Entre las revistas citadas, son de mencionarse: Sophía de la editorial Doble Hélice ${ }^{24}$ y Sophia, suplemento semanal del Heraldo de Chihuahua, ${ }^{25}$ Metamorfosis, ${ }^{26}$ algunos textos en Finisterre, ${ }^{27}$ Alétheia y Areté. ${ }^{28}$ Algunas colaboraciones de Synthesis, ${ }^{29}$ Cuadernos fronterizos ${ }^{30}$ y Nóesis, ${ }^{31}$ ésta última

24 Solo aparecieron dos números, entre 2000 y 2001.

25 Cf. http://www.oem.com.mx/elheraldodechihuahua/sophia.aspx

26 Publicada por la FFyL de la UACH. Cf. http://ffyl.uach.mx/pdf/metamorfosis_ convocatoria.pdf

27 Era publicada por el Centro de Información del Estado de Chihuahua, en la década de los ochenta y principios de los noventa.

28 Publicados por el Círculo de Investigaciones Jurídicas y Filosóficas. Para estas dos últimas Cf. http://www.cifyj.org/p/acerca-de.html

29 Editada por la Dirección de Extensión y Difusión de la UACH, cf. http://www. uach.mx/extension_y_difusion/synthesis/

30 Editada por el Instituto de Ciencias Sociales y Administración de la UACJ. Cf. Núm. 14, primavera de 2010 en el que aparece un dossier titulado La filosofía hoy, pp. 18-32.

31 Editada por el Instituto de Ciencias Sociales y Administración de la UACJ. Los números más recientes de la revista que tienen dicho enfoque son: Núm. 38, vol. 19, agosto-diciembre de 2010. La violencia: una visión desde la filosofía. Coordinado por Walter Beller Taboada y Margarita Salazar Mendoza. Núm. 42, vol. 21, agosto- 
es una revista de Humanidades y Ciencias Sociales que, desde hace algunos años, obtuvo la condición de indexada. Araucaria, Revista Iberoamericana de Filosofía, Política y Humanidades se edita en conjunto por El Colegio de Chihuahua, la Universidad de Sevilla, la UACH y la UACJ. Se publica desde 1999 y está incluida en índices de varios países del mundo. Pero, ha brillado el silencio de los filósofos chihuahuenses en sus páginas.

Debe ponerse atención a un comentario que Ferro Gay hizo en 1993 acerca de la investigación filosófica: “...debo decir que durante toda mi estancia en la escuela [1963-1984] no conocí trabajos de investigación que fueran efectivamente valiosos, o sea que se pudieran llamar de esta manera. Claro está que los alumnos escribían trabajos, pero eran los trabajos escolares, o sea los que debían presentar para cubrir los requisitos de las diferentes asignaturas. Y claro, algunos que escribían en revistas, periódicos, etcétera. Pero no vi, desgraciadamente, ningún trabajo profundo de investigación" ${ }^{32}$

ث) Congresos: Como se mencionó antes, es inédita la cantidad de congresos de filosofía profesional que aquí se han organizado en las últimas tres décadas. Se ha probado hasta la saciedad que se cuenta con los recursos materiales suficientes para armar foros en los que participen ponentes reconocidos internacionalmente. Empero, hay preguntas que considero necesario responder para ubicar dichos encuentros en un contexto más justo. Primero, ¿qué frutos se han cosechado localmente con la visita de reputados filósofos?, ¿ha mejorado el nivel académico?, ¿se ha elevado el nivel de discusión filosófica?, ¿aumentaron significativamente las exposiciones decorosas de chihuahuenses en congresos nacionales e internacionales fuera del estado y del país? Además, ¿qué tenían que decir los filósofos chihuahuenses en dichos foros?, ¿sus intervenciones fueron

diciembre 2012. Filosofía de las ciencias. Coordinado por Roberto Estrada Olguín, Alberto Escalera Narváez y Juan de Dios Viramontes Miranda. Y Núm. 45, vol. 23, enero-junio de 2014. La mitad de la edición Filosofía de las religiones fue coordinada por Jorge Ordóñez Burgos.

32 La filosofía en Chihuahua. Una conversación de Héctor Pedraza Reyes con Federico Ferro Gay. Cuadernos de Trabajo núm. 17, p. 11. UACJ, otoño de 1993. 
destacadas, motivaron investigaciones posteriores? Como los tópicos anteriores, estas preguntas no tienen respuesta fácil porque es menester construirla atendiendo al contexto y la historia individual de varias personas. Los casos aislados en forma alguna establecen una tradición. La mención de congresos es parte del recuento histórico de la filosofía occidental del último siglo, ¿con qué propósito se echa mano de este recurso en el estado de Chihuahua?

ج) Filósofos: Puesto que el objetivo de esta disertación no es hacer una historia de la filosofía, sino proponer esquemas que lleven a construirla, parto del supuesto que en Chihuahua hay filósofos en la actualidad y desde mucho tiempo antes que existieran estudios universitarios de filosofía en el estado. Sin embargo, es historiográficamente necesario que se señale quiénes son los filósofos que han creado pensamiento en los últimos cuarenta años, dónde se encuentran plasmadas sus ideas, qué proyección han tenido, en resumen, dar cuenta de por qué se les considera filósofos. Difícilmente se llegará a lograr consenso en este particular, sin embargo, la revisión documentada de la trayectoria de colegas brillantes ahorraría discusiones bizantinas. Creo que el más destacado de este período es José Fuentes Mares, pudiera discutirse si su trabajo literario e histórico es filosofía, este no es el espacio para hacerlo. Lo que es innegable es la sólida formación filosófica que lo respaldaba desde su regreso a Chihuahua a principios de los años cincuenta. Bajo el brazo traía, además de los títulos de maestro y doctor en filosofía por la UNAM, unas publicaciones nada despreciables, ${ }^{33}$ Fuentes Mares provenía del mundillo

33 El prólogo a Estudios de Gabino Barrena. UnAm. México, 1941. Ley, sociedad y política. Ensayo para una valoración de la doctrina de San Agustín en perspectiva jurídicopolítica de actualidad. Imprenta Universitaria, México, 1943. Kant y la evolución de la conciencia socio-política moderna. UNAM, 1946. Y México en la hispanidad. Ensayo polémico sobre mi pueblo. Ediciones de Cultura Hispánica, Madrid, 1949. Los artículos "San Agustín. Crítico del imperio romano". Revista de Estudios Universitarios. México, diciembre de 1939. "Trayectoria del pensamiento filosófico en el Méjico de nuestros días." Estudios Americanos, Vol. 1, Núm. 1. Sevilla, 1948. pp. 125-146. Además de varias reseñas de textos filosóficos publicados en la revista Filosofía y Letras de la UNAM, aparecidas a principios de los cuarenta. Cf. Jorge Ordóñez Burgos "José Fuentes Mares: actualización bibliográfica (1987-2012)”. Historia Mexicana, LXIII, 4, 2014, pp. 1993-2031. 
académico y sabía encajar en él. Es de señalarse que el profesor Ferro Gay no menciona este hecho cuando habla de la fundación de la Escuela de Filosofía y Letras de la UACH. "El único que podía considerarse como tal [filósofo], en un sentido muy lato era yo...El único que verdaderamente había recibido una formación filosófica escolarizada era el Padre Vargas". ${ }^{34}$

El profesor Federico Ferro Gay es una figura imprescindible en la historia contemporánea de la cultura del estado. La estatura de maestro transgeneracional lo define como pilar de lo que se hace en la actualidad. Sin embargo, es prácticamente nada lo que se le ha estudiado más allá de breves menciones anecdóticas o entrevistas. Extrañamente, a la fecha no se ha escrito una sola tesis sobre él. Sin ir más lejos, en la Enciclopedia Electrónica de la Filosofía Mexicana aparece su nombre en la lista de filósofos, pero, nadie se ha tomado la molestia de escribir un artículo. ${ }^{35}$ Las publicaciones de Ferro Gay no han tenido la misma suerte que las de Fuentes Mares, se han hecho compilaciones parciales, y, por cierto, no de mucha calidad. Por ejemplo, De lo divino en lo humano ${ }^{36}$ es un volumen en el que se avientan al lector conferencias, artículos y estudios sin la información que consigne datos mínimos como datación, el medio en que aparecieron originalmente y su relación con otros trabajos. ${ }^{37}$ Por último, el doctor Arturo Rico Bovio es, según mi entender, el filósofo vivo más importante del estado. Con formación jurídica y filosófica, ha creado pensamiento propio, más reconocido y estudiado fuera de su tierra que en ella. Ha participado en congresos nacionales y mundiales de filosofía, ha escrito diversos libros ${ }^{38}$ y publicado en revistas serías de diversos

34 La filosofía en Chihuahua, pp. 7-8.

35 Cf. http://dcsh.izt.uam.mx/cen_doc/cefilibe/index.php/filosofos-mexicanos

36 UACH-UACJ, 2003. Incluye una buena presentación hecha por el doctor Adrián Rentería Díaz "Federico Ferro Gay, el hombre y el maestro", pp. 9-19. Los compiladores de los textos fueron: Heriberto Ramírez, Sandra Heiras, René Bautista y David Alderete.

37 Lo mismo puede verse en un par de obras de Fuentes Mares publicadas por la UACH: Ensayos y discursos. Universidad Autónoma de Chihuahua. Chihuahua, 2002. Y Kant y la evolución de la conciencia socio-política moderna. UACH. Chihuahua, 2002. 38 Entre su obra es de mencionarse: i) La naturaleza de los derechos subjetivos. El substrato del real del orden jurídico. Tesis para obtener el grado de Licenciado en 
países: ${ }^{39}$ maestro incansable de filosofía en la UACH y en otras universidades del país.

Mucho se habla de la existencia de una "línea analítica" como eje conductor de la FFyL de la UACH, algunos establecen cierta genealogía cuyo origen es el profesor Enrique Pallares. Por lo general se asumen posturas de rechazo o adhesión a la "corriente", si pudiera llamársele así. No obstante, tampoco existen estudios serios sobre los planteamientos que sostiene -tanto en el terreno filosófico como educativo-, tampoco se ha hecho un recuento de sus publicaciones, si es que las hay. ${ }^{40}$

Derecho. Escuela de Derecho. Universidad Autónoma de Chihuahua. Chihuahua, agosto de 1967. Texto inédito, el original se conserva en el Fondo Federico Ferro Gay de la Biblioteca Central de la Universidad Autónoma de Ciudad Juárez. Núm. Clasificación KGF 8566 R53 1967. CEBCE 13; ii) Las fronteras del cuerpo. Crítica de la corporeidad. Joaquín Mortiz. México, 1990; iii) La hora del desierto - germinarlo-. Plaza y Valdés. México, 1991; iv) Teoría corporal del derecho. Facultad de Derecho de la UAcH/ Miguel Ángel Porrúa. México, 2000; v) Tránsito filosófico: de la crisis a la esperanza. Sindicato del Personal Académico de la Universidad Autónoma de Chihuahua/Miguel Ángel Porrúa. Chihuahua, 2008.

39 Entre sus artículos y capítulos de libros están: i) "Las coordenadas corporales. Ideas para pensar el ser humano". Contenido en la Revista de Filosofía de la Universidad de Costa Rica, pp.89-96. Núm. XLIII. San José, enero-abril de 2005; ii) "Diálogo imaginado con Horacio Cerutti". Contenido en el libro Filosofía, utopía y política. En torno al pensamiento y a la obra de Horacio Cerutti Guldnerg, coordinado por Rubén García Clarck, Luis Rangel y Kande Mutsaku. pp. 121-130. Iztacala/UnAM. México, 2001; iii) "Propuesta para un rescate crítico de la cultura latinoamericana", contenido en América Latina: identidad y diferencia. Actas del Primer Congreso Internacional de Filosofía Latiniamericana, 1990, pp. 99-104; iv) "Fundamentación de las revoluciones sociales. Ponencia presentada en el II Coloquio Nacional de Filosofía de Monterrey, Nuevo León". Metamorfosis, núm. 13, época III, octubre de 1981, pp. 6-12. Escuela de Filosofía y Letras, UACH. Chihuahua.

40 Enrique Pallares publicó en 2000 Perfiles de la cultura contemporánea. Filosofía de la cultura. UACH. En la introducción del libro, el autor señala "Este escrito es el producto de al menos cuatro años de trabajo con algunas interrupciones y primeros intentos". La obra citada es el único texto que ha generado la llamada "línea analítica". Refiero el comentario de Pallares porque los orígenes de dicha tendencia se remontan a mediados de los setenta, y, no es hasta un cuarto de siglo después que aparece el primer libro. -Víctor Hernández Márquez ha desarrollado investigaciones en esta línea, no obstante, su labor ha trascendido el ámbito estatal. De origen, perteneció al círculo de Pallares, sin embargo, sus estudios de posgrado se nutrieron de otras fuentes. Entre sus obras son de citarse: Lógica, lenguaje y realidad. Examen crítico del programa absolutista, Universidad Autónoma de Chihuahua, Chihuahua, 2001. Reseñado por Alejandro Tomasini Bassols. Dianoia, Núm. LXVII, núm. 49, noviembre de 2002, pp. 183-191. Cf. http://dianoia.filosoficas.unam.mx/ files/6913/6244/1776/DIA49_Resena_Tomasini.pdf Y Fronteras y reconstrucciones en la filosofía de la ciencia, referido anteriormente. 
z) Historias de la filosofía: es poco lo que se ha escrito en Chihuahua sobre los filósofos chihuahuenses, a pesar de que somos nosotros los principales interesados en hacer un recuento crítico de las ideas aquí gestadas, no se ha trabajado en la construcción de una historia de las ideas, o, si se quiere, de la filosofía. En 1993, Héctor Pedraza Reyes con entusiasmo anunciaba el inicio de una historia de las ideas partiendo de los orígenes de la FFyL de la UACH, cuyo primer y único movimiento del primer bloque temático fue la entrevista a Ferro Gay citada anteriormente: "El primer paso para establecer su relevancia en la historia de las ideas consiste, precisamente, en reconstruir su trayectoria a través de los testimonios de sus fundadores y de todos aquellos maestros y alumnos que han dedicado parte de su vida al desarrollo y fortalecimiento de esa institución educativa". ${ }^{41}$

Walter Beller publicó en 2010 Por el camino del método. Porfirio Parra, un chihuahuense universal. ${ }^{42} \mathrm{El}$ primer y, a mi parecer, único trabajo de historia de la filosofía encargado de un filósofo local. Es una contribución valiosa que marca pauta para estudios posteriores. Carlos Ordóñez ha publicado en años recientes una serie de artículos de divulgación sobre filósofos chihuahuenses del siglo XIX y XX ${ }^{43}$ en la sección Sophía de El Heraldo de Chihuahua. Un trabajo encomiable que todavía no se ha visto reflejado en monografías críticas provistas de referencias documentadas y revisión de fuentes. El 22 de septiembre de 2013, Ordóñez lanzó una invitación a sus lectores: “...un grupo de jóvenes investigadores hemos tomado este reto, y salido a las calles -o más bien bibliotecas y archivos-, para encontrar a los culpables de la existencia de un pensamiento local. Para ello preparamos el siguiente año un

41 P. 5.

42 UACJ.

43 Cf. “¿Existe una filosofía chihuahuense? http://www.oem.com.mx/elheraldodechihuahua/notas/n3123755.htm, “¡Hay filosofía en Chihuahua!” http://www.oem.com. mx/elheraldodechihuahua/notas/n3130872.htm, "José Fuentes Mares" http://www. oem.com.mx/elheraldodechihuahua/notas/n3139266.htm, "Pedro Zuloaga y la ciencia" http://www.oem.com.mx/elheraldodechihuahua/notas/n3180169.htm, "Laureano Muñoz" http://www.oem.com.mx/elheraldodechihuahua/notas/n3387371.htm, "Porfirio Parra" http://www.oem.com.mx/elheraldodechihuahua/notas/n2783201.htm, "Arturo Rico Bovio" http://www.oem.com.mx/elheraldodechihuahua/notas/n2506038.htm. 
trabajo especial en las centrales de Sophía y proponemos a nuestros lectores que se unan a la Línea de Investigación de Filosofía Chihuahuense". 44

\section{CONCLUSIONES}

La filosofía es una disciplina que está obligada a cuestionarse a sí misma, seguido olvidamos este principio elemental. Si hablamos de un pensamiento local, lo más natural será preguntar qué hacen los filósofos chihuahuenses; ha existido gran reticencia para abordar el tema, a pesar que sí podemos encontrar trabajos de buen nivel en el estado. Nuestra historia de las ideas está por escribirse, hay recursos de gran valor que se omiten patológicamente. Por ejemplo, las tesis de la licenciatura en filosofía inéditas que esperan ser desempolvadas y otras que fueron tiradas a la basura, perdiéndose para siempre. ¡Podemos enorgullecernos en Chihuahua de haber tenido nuestra propia tragedia alejandrina! El rescate o reconstrucción parcial de este acervo servirá para entender el presente. Por otro lado, el diálogo real y abierto con artistas, científicos y personas que puedan aportar algo a la reflexión aún no se ha iniciado. La filosofía no solo se construye a partir de tratados y sistemas, y si así fuera, invoco las palabras de Onfray, puestas a manera de epígrafe.

Es necesario superar la inercia de pasar de lado todo lo que se escribe en Chihuahua, con ello no pretendo hacer un llamado a la concordia y la harmonía, existen facciones, grupos e intereses que no desaparecerán. Lo importante es reconocer que hay aportaciones valiosas en nuestro estado y que la simulación ha causado estragos. En Chihuahua es necesario hacer una historia del pensamiento, una que no caiga en el extremo de despreciar o alabar sistemáticamente todo lo que aquí se produce. Con frecuencia, se llega a uno de los polos sin la menor justificación.

Otro criterio historiográfico, que podría dimensionar con mayor claridad el desenvolvimiento de la filosofía académica en el estado, es la comparación con otras comunidades similares. Qui-

44 http://www.oem.com.mx/elheraldodechihuahua/notas/n3130872.htm 
zá la más cercana es la Escuela de Historia de la UACJ, fundada hace menos de veinte años. Pudiéndosele abordar a través de los mismos criterios arriba propuestos.

En la introducción del volumen de las memorias del II Encuentro de Filosofía de la Zona Norte de México, Alejandra Olivas y Heriberto Ramírez comentan: "En el marco de este análisis emerge una relación estrecha entre filosofía y futuro, esto es, la responsabilidad de la primera para la mejora del segundo... ¿qué puede hacer la filosofía con el futuro como proyecto?... tenemos la esperanza de que contribuya a la construcción de un escenario más favorable para la enseñanza y la práctica de la filosofía”. ${ }^{45}$ Antes de hablar del futuro, es menester voltear la mirada al pasado y poner los pies en el presente. No puede hablarse de una filosofía del mañana si no ha habido una del ayer, el pensamiento se ha convertido en una tarea por hacer más que en una forma de vivir.

45 Pp. 9-10. 